3

4

6

7

8

9

10

11

12

13

14

\section{Graphical Abstract}

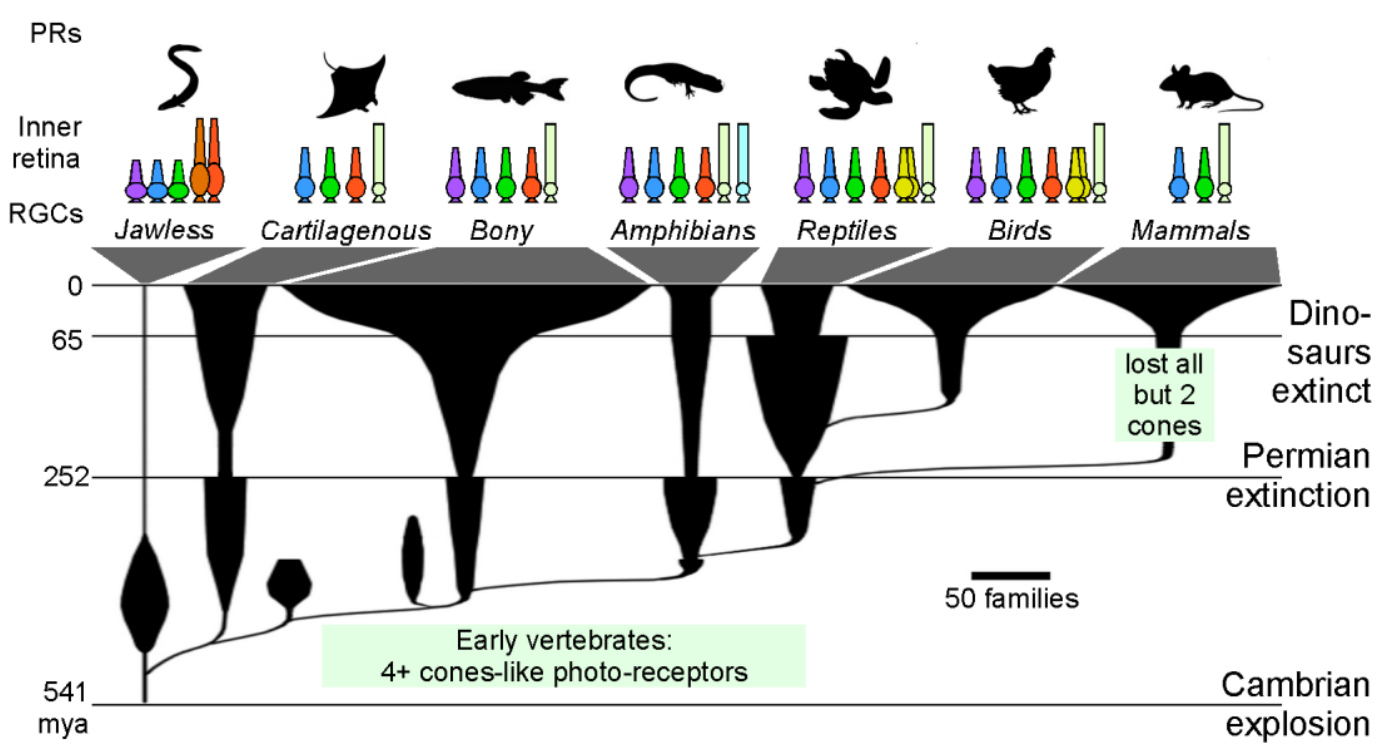

\author{
Baden $\mathrm{T}^{1,2}$ and Osorio $\mathrm{D}^{1}$
}
1: School of Life Sciences, University of Sussex, UK; 2: Institute for Ophthalmic Research, University of Tuebingen, Germany

45 Pages

381 Words (Abstract)

8242 Words (Main text and Figure Legends)

191 References

4 Color Figures

Key words: Color vision, Cone photoreceptors, Opponency, Retina

\title{
The retinal basis of vertebrate color vision
}




\section{SUMMARY}

Vertebrate color vision is evolutionarily ancient. Jawless fish evolved four main spectral types of cone photoreceptor, almost certainly complemented by retinal circuits to process chromatic opponent signals. Subsequent evolution of photoreceptors and visual pigments are now documented for many vertebrate lineages and species, giving insight into evolutionary variation and ecological adaptation of color vision. We look at organization of the photoreceptor mosaic and the functions different types of cone in teleost fish, primates, and birds and reptiles. By comparison less is known about the underlying neural processing. Here we outline the diversity of vertebrate color vision and summarize our understanding of how spectral information picked up by animal photoreceptor arrays is adapted to natural signals. We then turn to the question of how spectral information is processed in the retina. Here, the quite well known and comparatively 'simple' system of mammals such as mice and primates reveals some evolutionarily conserved features such as the mammalian Blue ${ }^{\mathrm{ON}}$ system which compares short and long wavelength receptors signals.

We then survey our current understanding of the more complex circuits of fish, amphibians, birds and reptiles. Together, these clades make up more than $90 \%$ of vertebrate species, yet we know disturbingly little about their neural circuits for colour vision beyond the photoreceptors. Here, long-standing work on goldfish, freshwater turtles and other species is being complemented by new insights gained from the experimentally amendable retina of zebrafish. From this body of work, one thing is clear: The retinal basis of colour vision in non-mammalian vertebrates is substantially richer compared to mammals: Diverse and complex spectral tunings are established at the level of the cone output via horizontal cell feedforward circuits. From here, zebrafish use cone-selective wiring in bipolar cells to set-up color opponent synaptic layers in the inner retina, which in turn lead a large diversity of color-opponent channels for transmission to the brain. However, while we are starting to build an understanding of the richness of spectral properties in some of these species' retinal neurons, little is known about inner retinal connectivity and cell-type identify. To gain an understanding of their actual circuits, and thus to build a more generalised understanding of the vertebrate retinal basis of color vision, it will be paramount to expand ongoing efforts in deciphering the retinal circuits of non-mammalian models. 


\section{Introduction}

'...the belief that organic beings have been created beautiful for the delight of man, .... has been pronounced as subversive of my whole theory, ... C Darwin. Origin of Species. Ch. 6.'

Study of the evolution and function of animal color vision originates from two nineteenth century insights into the imperfections of nature. In 1803 Thomas Young saw that measurement of the spatial location and the spectral composition of a light are fundamentally incompatible, and proposed trichromacy as the best compromise (Mollon 2003). Young also recognised that the spectrum extends to wavelengths beyond the range that humans can see. We do not know if Young directly influenced Darwin, but the idea that living organisms are imperfect was a mainspring of his theory of evolution (Darwin 1859), because natural selection could not change a perfect mechanism.

As an easily recognised character, $19^{\text {th }}$ century evolutionary biologists took a keen interest in animal and plant coloration (Cronin 1991, Prum 2012). Why, for example, are some animals camouflaged when others have conspicuous coloration, and why do the sexes sometimes differ in their appearance? If coloration evolved by natural selection the same would apply to color vision. Wallace (Wallace 1879), noting the colors of foods eaten by different animals, observed that primates alone amongst mammals have 'tolerably perfect' color vision, and that this was 'probably inferior to that of birds'. We now know that most mammals have two spectral types of cone photoreceptor, many primates have three, and birds have four or five (Fig. 1).

The stimulating influence of Darwinism on research into animal color vision is exemplified by Darwin's friend and neighbour John Lubbock, a politician and gentleman naturalist, whose finding that ants moved their pupae away from UV light was the first demonstration that an animal could see beyond the human visible spectrum (Lubbock 1882). Later Lubbock found that water fleas (Daphnia) prefer yellow light to white independently of intensity, and argued that this behaviour can be regarded as color vision (Kelber \& Osorio 2010, Lubbock 1889).

Color vision remains a powerful system for investigating how animal senses evolve under natural selection. Photoreceptor spectral tuning is known for many species, and there is a direct relationship between the genotype (the opsin DNA sequence) 
and the photopigment spectral sensitivity. In addition, we can record the reflectance spectra of objects encountered by an animal in its daily life, and estimate receptor responses to them, thereby specifying the signals available to the brain. A wealth of studies on opsin evolution, and the ecological influences on photoreceptor spectral sensitivities (Bowmaker 2008, Osorio \& Vorobyev 2008), is complemented by behavioral tests which show how photoreceptor signals are used for color and luminance vision (Kelber et al. 2003). In parallel, physiological studies of the retina have addressed questions about selective wiring, chromatic opponency and other aspects of color processing beyond the receptors, especially in mice and primates. In the future it will be important to extend retinal physiology across vertebrate phylogeny, especially to branches such as teleost fish and birds, which feature rich spectral receptor complements, and make much use of color vision (Fig. 1).

\section{Behavioural study of animal color vison}

Until about 1980 psychophysical studies of human and animal color vision often had differing objectives, exemplified in key texts by Wyszecki and Stiles (1982) Color Science, and Jacobs' (1981) Comparative Color Vision. For humans the existence of color vision is not in doubt, and researchers were interested in mechanisms, starting with trichromacy and chromatic opponency, and extending to color constancy, color categorization and color appearance (Brainard \& Stockman 2010, Gegenfurtner \& Kiper 2003, Wyszecki \& Stiles 1982). In animal research early work such a Lubbock's (Lubbock 1889) findings on Daphina posed the question of whether a simple response to the spectral composition of a light can be described as color vision. We have no access to Daphnia's (or any other species') experience of color, so studies focussed on whether a given species had color vision (Jacobs 1981). Usually these entailed training an animal to associate a reward with a particular spectrum, and then testing it against a range of greys. According to this criterion a wide range of animals tested see color (Kelber et al. 2003). Studies have also measured color discrimination thresholds, either for the wavelength difference between two monochromatic lights $(\delta \lambda)$, or of monochromatic light added to an achromatic background (spectral sensitivity) (Kelber et al. 2003). More recently interest has moved to questions about color constancy (Chittka et al. 2014, Dörr \& Neumeyer 2000, Olsson et al. 2016), color generalization (Baddeley et al. 2007, 
118 Caves et al. 2018, Jones et al. 2001), and the ways in which specific sets of receptors serve particular behaviours (Orger \& Baier 2005, Zimmermann et al. 2018).

For non-human species it has however not been possible to use psychophysical methods to determine the spectral sensitivities of the color mechanisms (i.e. photoreceptors), which underpins work on human color vision (Wyszecki \& Stiles 1982). Research therefore benefits greatly from direct measurement of photoreceptor spectral sensitivities (Part 1), because spectral stimuli can then be defined in terms of receptor excitations. An important empirical finding is that color discrimination thresholds can often be predicted from receptor responses by assuming that they are set by noise arising from photoreceptors in (unspecified) in chromatic opponent channels, disregarding the achromatic/luminance signal (Olsson et al. 2018, Vorobyev \& Osorio 1998). If this 'receptor noise' model describes experimental data this implies that the use of receptor signals is ideal, so it is not possible to make inferences about post receptoral mechanisms from experimental data. Conversely, deviations from the predictions of the model can give insight into higher level mechanisms, such as color categorization and generalization (Baddeley et al. 2007).

\section{Part 1: Photoreceptors}

Evolution of photoreceptor spectral sensitivities

Ecological study of photoreceptor spectral sensitivities began in the 1930's with the 'sensitivity hypothesis', which proposed that fish sensitivities match the ambient illumination (Clarke 1936, Collin et al. 2009, Loew \& Lythgoe 1985, Luk et al. 2016). This subject is now grounded in evolutionary genetics, and has gone on to examine the relation of receptor sensitivities to reflectance spectra of objects relevant to a given species as well as to illumination (Davies et al. 2012, Lind et al. 2017, Nathans et al. 1986, Ödeen \& Håstad 2003, Osorio \& Vorobyev 2008). Here we give a brief background.

Visual pigments are G-protein coupled receptors, known as opsins, which bind a chromophore, namely retinal or a related carotenoid molecule (Arshavsky et al. 
2002). Spectral tuning of the pigment is defined as the probability that a photon of a given wavelength incident on the molecule is absorbed by the chromophore to initiate the light response. This tuning is affected by the amino acid residues at key sites on the opsin protein (Patel et al. 2018, Porter et al. 2007, Wilkie et al. 2000, Yokoyama 2000). Opsin spectral tuning has only one degree of freedom, and is normally specified by the value to peak absorbance, $\lambda$ max (Govardovskii et al. 2000, Patel et al. 2018).

Photoreceptor spectral sensitivities should ideally be measured from intact eyes, and in vivo electrophysiological recordings are common in arthropods (Autrum \& Zwehl 1964), but the anatomy of the vertebrate eye makes such recordings difficult, so most studies measure visual pigment spectral absorbance by spectrophotometry of an isolated cone's outer segment (Bowmaker 1984), or infer it from the DNA sequence (see above).

Comparative studies of vertebrate opsin and photoreceptor spectral sensitivities find a striking combination of evolutionary conservatism and adaptive change (Lind et al. 2017, Osorio \& Vorobyev 2008). Some 500 million years ago the jawless fish which were ancestral to modern vertebrates evolved four classes of cone opsin, designated SWS1 ('UV/Violet'), SWS2 ('Blue'), MWS/RH2 ('Green') and LWS ('Red') (Bowmaker 2008, Davies et al. 2012, Lamb 2013, Okano et al. 1994, Yokoyama 2000). Rod $(\mathrm{RH} 1)$ opsins probably evolved from the $\mathrm{RH} 2$ opsins after the lineages of contemporary jawed vertebrates (gnathostomes) and lampreys (agnathans) diverged, so early gnathostomes saw the world through four sets of cone photoreceptors, and one rod. Contemporary vertebrates retain different subsets of the four cone pigment families, as well as rods (Fig. 1). For example, whereas most mammals have only LWS and SWS1, many teleost fish, amphibians, reptiles and birds have the full ancient complement. Animals that live in dim conditions or in open water, including various fish, penguins, burrowing snakes and nocturnal mammals, typically have fewer spectral photoreceptor types (Bowmaker 2008, Davies et al. 2012). Groups that have reduced their cone-complement to but a single class, or even none, include marine mammals, like whales and seals, as well as many sharks (Griebel 2002, Griebel \& Peichl 2003, Meredith et al. 2013, Theiss et al. 2012), and also smaller terrestrial species like beavers or racoons (Peichl 2005). In teleosts and primates the number of opsin genes is increased by gene duplication (Chinen et al. 
183

184

185

186

187

188

189

190

191

2003, Nathans et al. 1986). Having multiple opsin genes fish vary pigment expression ontogenetically, sometimes under control of the ambient illumination (Shand et al. 2008, Spady et al. 2006). Normally there are no more than four spectral types of cone in a given retina, each expressing a cone typical opsin gene: $L$ cones ("red", R, LWS opsin), M cones ("green", G, MWS/RH2 opsin), S cones ("blue", B, SWS2 opsin) and UV cones ("ultraviolet", UV, SWS1 opsin). A notable exception is bird/reptile double cones, which express LWS opsin. Finally, vertebrate rods $(\mathrm{RH} 1$ opsin) can also contribute to color vision (Part 2), and a second type of rod found in some amphibians (Korenyak \& Govardovskii 2013, Yovanovich et al. 2017).

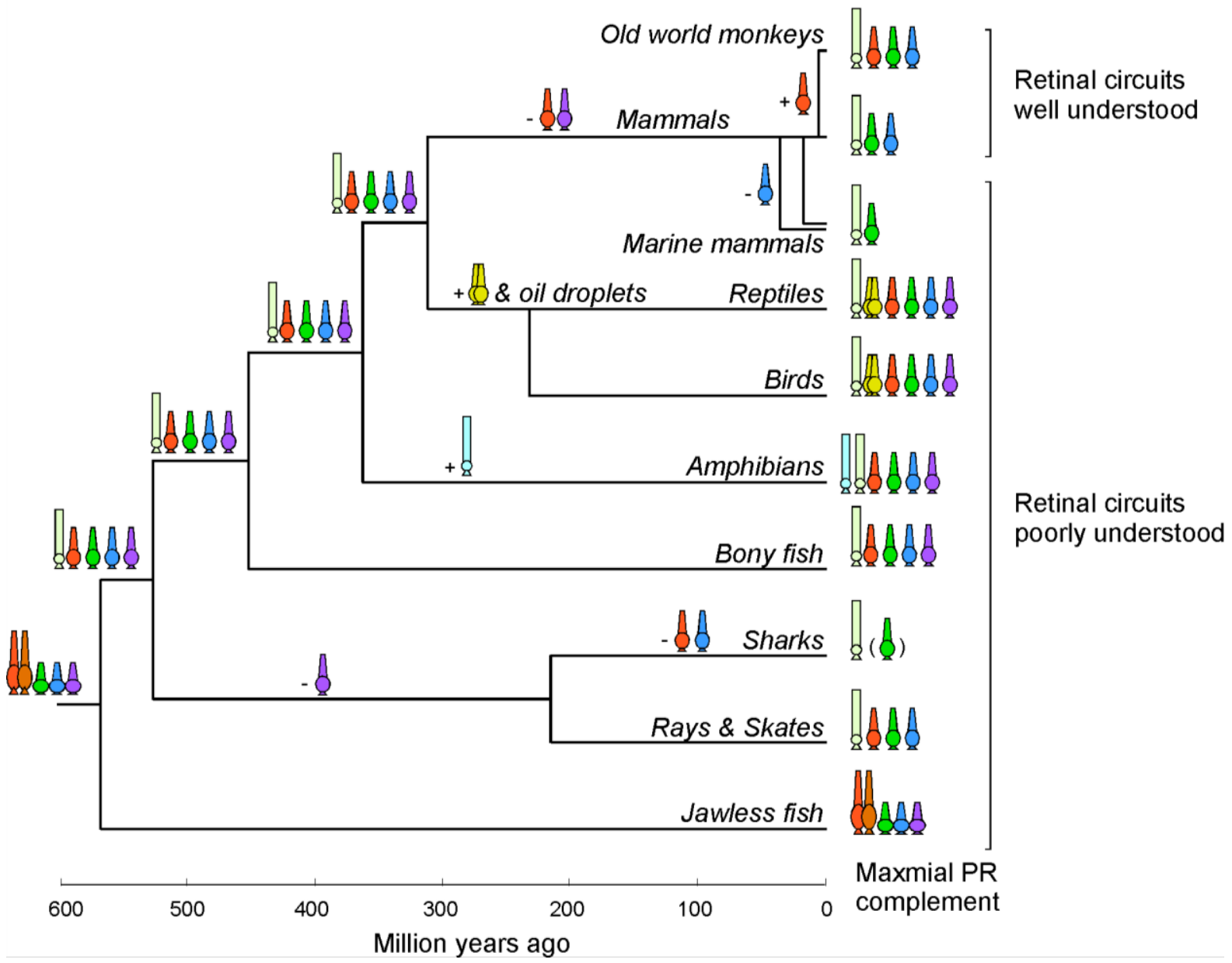

Figure 1 - Photoreceptor lineages. The ancient photoreceptor complement present in jawless ancestral vertebrates (leftmost) gave rise to the photoreceptor complements present in jawed vertebrates today (right). Along the way, different lineages added or lost types of photoreceptors at different timepoints. Rods (beige), L-cones (red), M-cones (green), S-cones (blue), UV-cones (purple), "blue” rods (light blue), "double-cones” (yellow). Photoreceptor (PR) complements shown depict the typical maximal diversity in a lineage - often individual groups use fewer. 
201

202

203

204

205

206

207

208

209

210

211

212

213

214

215

216

217

218

219

220

221

222

223

224

225

226

A

Genetic variation

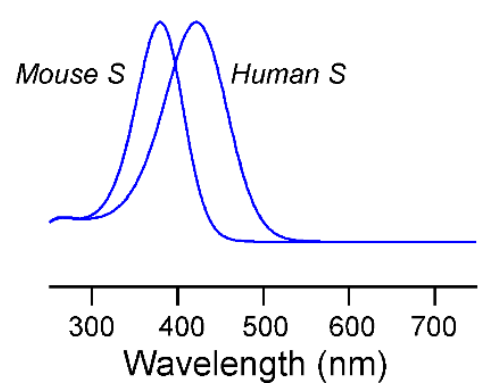

B

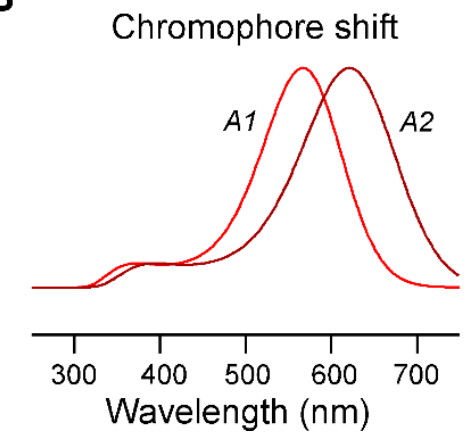

C

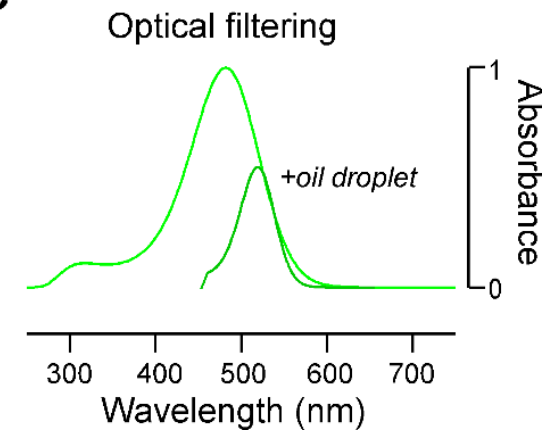


Figure 2 - Opsin Tuning. A, Opsins of the same lineage can exhibit different spectral peaks due to differences in the opsin gene sequence - here illustrated for SWS-opsins of mice and men. B, Depending on the chromophore used, the same opsin can exhibit different spectral tunings - here illustrated for a zebrafish LWS opsin using either 11-cis-retinal (A1) or 11-cis3,4-didehydroretinal (A2). C, Addition of filtering media such as oil droplets can further be used to shape a photoreceptor's spectral absorbance, here illustrated in for an avian M-cone.

\section{Receptor specialisation and retinal mosaics}

The array of photoreceptors in the vertebrate retina has to sample both spatial and spectral signals, and so should reflect the compromises between these roles that suit animals' particular needs, as well as developmental constraints (Rister \& Desplan 2011). The following examples from primates, fish, birds and reptiles illustrate some of the organisational principles in photoreceptor function and mosaics in these major vertebrate groups. Part 2 looks further at the particular cases of mouse and larval zebrafish in relation to their retinal circuitry.

\section{Old world monkeys}

Old-world monkeys are trichromats with opsin spectral sensitivity maxima at about $440 \mathrm{~nm}$ (in S/blue cones), $554 \mathrm{~nm}$ (in M/green cones) and $565 \mathrm{~nm}$ (in L/red cones). As elaborated below (Part 2) this cone-complement produces to two classical spectral channels: the "ancient" blue-yellow axis and a primate-specific red-green axis. A further distinction is made between chromatic and luminance mechanisms (Lee et al. 1990, Livingstone \& Hubel 1988, Mullen \& Losada 1994). Primates are unusual because the red-green system evolved from the dichromatic ancestral mammalian LWS system by the acquisition of separate $L$ and $M$ cones, without commensurate change in retinal anatomy (Mollon 1989). Wiring of $L$ and $M$ cone outputs is largely non-selective (See Section 2) (Field et al. 2010), and they are integrated to produce a luminance signal which serves many aspects of vision, notably by the parasol ganglion cells, which project to the magno-cellular layers of the lateral geniculate nucleus (LGN). Here, spectral sensitivity differences of the inputs are of no benefit and may corrupt the luminance signal (Gegenfurtner \& Kiper 2003, Lee et al. 1990, Osorio et al. 1998). In parallel, chromatic information is transmitted via 'blue-yellow' opponent ganglion cells (Dacey 2000, Dacey \& Lee 
261

262

263

264

265

266

267

268

269

270

271

272

273

274

275

276

277

278

279

280

281

282

283

284

285

286

287

288

289

290

291

292

293

1994), and 'red or green' midget ganglion cells which project to the parvocellular layers of the LGN (Derrington et al. 1984, Gegenfurtner \& Kiper 2003, Lee et al. 2017) (Fig. 3a,b). The midget system, probably evolved as a primate specialisation for spatial acuity, transmits single $L$ and $M$ cone outputs to the brain, where they are integrated by activity dependent plasticity (Doi et al. 2003, Mollon 1989, Wachtler et al. 2007), without specific retinal circuits to separate luminance and red-green chromatic signals. The mosaic of $L$ and $M$ cones is random (Roorda \& Williams 1999), but in macaque the $S$ cone array is semiregular (Martin \& Grunert 1999). Darwin might have been pleased that anatomically our red-green system seems poorly designed. So far as we know such an arrangement is not present in any other vertebrate visual system, where it is usual to find orderly receptor mosaics driving specialised retinal circuits.

\section{Goldfish, zebrafish and triggerfish}

Goldfish and zebrafish belong to the carp family (Cyprinidae). Adults have four spectral types of cones arranged in a regular mosaic (Engström 1963) with alternating rows of double cones with Red (LWS) and Green (MWS) members, and Blue (SWS2) and UV (SWS1) single cones, giving twice as many Red and Green cones as Blue and UV (Allison et al., Raymond et al. 1993). In goldfish, spectrophotometry of cone outer segments gives respective sensitivity maxima of $623 \mathrm{~nm}, 537 \mathrm{~nm}, 447 \mathrm{~nm}$ and $356 \mathrm{~nm}$ (Palacios et al. 1998). Zebrafish have shorter wavelength peaks at about $565 \mathrm{~nm}, 477 \mathrm{~nm}, 415 \mathrm{~nm}$ and $360 \mathrm{~nm}$ (Meier et al. 2018), but gene duplication allows these fish - like many others - to express different variants in a given cone (Bowmaker 2008, Chinen et al. 2003, Parry et al. 2005).

The presence of four types of cone pigment does not automatically entail tetrachromatic color vision - which requires that four primaries are needed to match any spectrum, but (Neumeyer 1992) showed that a mixture of four monochromatic lights was needed for goldfish to match a white (spectrally flat) light. She also found evidence for three separate chromatic opponent mechanisms by training to single monochromatic lights and testing the intensity ratio of pairs of monochromatic light needed for the fish to make a match. Further, tests under low photopic adapting illumination for discrimination of monochromatic lights $(\delta \lambda)$ wavelength also suggest 
that goldfish are tetrachromats with sensitivity maxima at about $415 \mathrm{~nm}, 500 \mathrm{~nm}$ and $605 \mathrm{~nm}$ (Neumeyer 1986). The long wavelength sensitivity maximum is lost at illumination intensities in the middle of the human mesopic range (Neumeyer \& Arnold 1989), when the fish fail to discriminate between $555 \mathrm{~nm}$ and $663 \mathrm{~nm}$, implying that signals of the two members of the double cone become functionally coupled. Similarly, zebrafish retain separate double-cone $R$ and $G$ signals in the inner retina (Zimmermann et al. 2018), but their optomotor (movement) response appears to sum R and $G$ signals (Orger \& Baier 2005). It is however not clear whether the red+green tuning of the optomotor response is indicative of a general luminance system akin to that in primates. In the fishes natural environment, the main source of optic flow information) is the long-wavelength biased ventral visual field, but the inner retina of larval zebrafish also has several systems with 'fully' achromatic responses that involve all four spectral receptors, rather than 'just' red and green (Zimmermann et al. 2018). Notably, unlike adults, but like in many other vertebrates, larval zebrafish have different density distributions of photoreceptor types in different parts of their eye, presumably to capitalise on different wavelength composition in natural light and different behavioural demands across their large visual field (Zimmermann et al. 2018).

Not all fish are tetrachromats. For example, the triggerfish Rhinecanthus aculeatus has three types of photopigment in two types of cones: single cones with a peak sensitivity at $413 \mathrm{~nm}$, and double cones which have two outer segments with sensitivity maxima at about $480 \mathrm{~nm}$ and $528 \mathrm{~nm}$ (Cheney et al. 2013, Pignatelli et al. 2010). Color discrimination tests find that triggerfish are trichromats (Champ et al. 2016), implying that as in the cyprinids this species retains separate double-cone $R$ and $G$ signals.

\section{Birds and Reptiles}

Birds and many reptiles have four types of single cone and one type of double cone, each of which is associated with a specific type of oil droplet that acts as a spectral filter by cutting off wavelengths below a certain value (Wilby \& Roberts 2017). This filtering narrows spectral tuning of the receptor, at the cost of absolute sensitivity (Hart \& Vorobyev 2005) (Fig. 2c). Each single-cone type contains a photopigment belonging to one of the four main vertebrate opsin families (Fig. 1) (Bowmaker et al. 
1997, Hart \& Hunt 2007, Toomey et al. 2015), with two main forms of the UV (SWS1) opsin giving peak sensitivities at about either $365 \mathrm{~nm}$ or $410 \mathrm{~nm}$ (Kram et al. 2010, Ödeen \& Håstad 2003, Wilkie et al. 2000). Bird photoreceptor spectral sensitivities in vivo are normally estimated by modelling the sensitivity based on the opsin and oil droplet absorption functions (Hart \& Vorobyev 2005, Toomey et al. 2016), which predicts $\lambda_{\max }$ values of $365 \mathrm{~nm}$ or $410 \mathrm{~nm}$ (SWS1, UV or violet), $440 \mathrm{~nm}-475 \mathrm{~nm}$ (SWS2, blue), $545 \mathrm{~nm}$ (MWS, green) and $605 \mathrm{~nm}$ (LWS, red). The UV type SWS1 receptors are associated with shorter wavelength SWS2 receptors, whereas the MWS receptor peaks vary little between species. The double cones contain LWS pigments and oil droplets which gives them a spectral sensitivity much like that of human $L$ (red) photoreceptors.

The cone mosaic in the chicken (and other birds) is orderly but less regular than that of fish. The mosaic is consistent with a model where each cone type forms a fairly regular hexagonal array that is independent of each of the other four types (Jiao et al. 2014, Kram et al. 2010). The densities of these arrays differ between cone types. In chicken, double cones represent about $40 \%$ of the total, and of the remainder densities fall in the order LWS $>M W S>S W S>V / U V S$, with the density of LWS cones being about two to four times that of the V/UVS (Hart 2001). There is however substantial variation between species, and across position in the visual field (Hart 2001).

Behavioural tests of color discrimination thresholds in pigeons, parrots and chickens suggest that, like goldfish, birds have tetrachromatic color vision based on the outputs of the four single cones (Goldsmith \& Butler 2003, Olsson et al. 2015, Vorobyev \& Osorio 1998). Tests with stimuli designed to reveal interactions between specific pairs of cones likewise imply that chickens have three spectral opponent mechanisms which compare UV vs. $S, S$ vs. $(L+M)$ and $L$ vs. $M$ cones, which is consistent with tetrachromacy (Osorio et al. 1999). Whereas fish double cones contribute to color vision, bird double cones may serve an achromatic system which is used for form and motion vision, resembling the primate luminance pathway (Jones \& Osorio 2004). This conclusion is however open to question, for example the fovea of the Harris hawk (Parabuteo unicinctus) is free of double cones but has a high spatial acuity and poor color vision (Potier et al. 2018). Similarly, the high acuity lower facing frontal visual field in pigeons, where the birds peck for food, is 
dominated by red cones and is probably predominantly luminance sensitive (Remy \& Emmerton 1989, Vorobyev \& Osorio 1998).

The retinal organisation and receptor spectral sensitivities of anole lizards are essentially identical to those of birds (Bowmaker et al. 2005, Loew et al. 2002), suggesting that this organisation evolved in the common ancestor of the two main lineages of living reptilles. Tests of wavelength discrimination by the freshwater turtle (Pseudymys scripta) suggests that, as in birds, four spectral receptor types contribute to color vision (Arnold \& Neumeyer 1987, Zana et al. 2001).

\section{Principles of spectral coding}

Before turning to the physiology of these systems in the vertebrate retina it is useful to look briefly at underlying principles of spectral coding by photorecptors, and then chromatic oppoency in the retina

When Young suggested that ideally color vision should have an 'infinite' number of spectrally tuned receptors he was unaware of the nature of the spectral stimuli in the natural world. To operate efficiently any coding system should be matched to the characteristics of the signals that it encodes (Barlow 1961, Simoncelli \& Olshausen 2001). It follows that the specific set of receptors in a given eye should depend upon the characteristics of the spectra that the animal needs to discriminate. In practice the reflectance spectra of natural materials vary smoothly with wavelength, and this lack of 'spectral detail' means that three receptors capture a large proportion of the available spectral information (Maloney 1986, Vorobyev et al. 1997). In addition, the spectra of many biological pigments tends to vary more at long than at short wavelengths. Consequently, primate trichromacy may in fact be close to the ideal for discrimination fruit and leaves (Osorio \& Vorobyev 1996), with the small spectral separation of the $L$ and $M$ receptors well suited to capturing this specific type of spectral information. Similarly, avian color vision with four (single) cone types narrowed by colored oil droplets is well suited to discriminating amongst the reflectance spectra of feathers, which can have more spectral variation than most objects (Osorio \& Ham 2002, Vorobyev et al. 1998).

Given a set of receptors that are suitably tuned to measure variation in natural spectra, how should their signals then be encoded by the second-stage of color 
vision? Having broadly tuned spectral receptors to sample smoothly varying spectral reflectance functions means that outputs of different spectral receptor are highly correlated (Barlow 1982, Maloney 1986, Srinivasan et al. 1982). A general principle of early stages of visual processing is to remove redundancy in neural signals caused by statistical correlations of this kind (Atick et al. 1992, Buchsbaum \& Gottschalk 1983). Thus, lateral inhibition, which produces the centre-surround receptive fields of many retinal neurons can be understood as a means of removing spatial correlation (Srinivasan et al. 1982). In the spectral domain at a basic level, correlations in the signal received by distinct spectral cones are removed before any extraction of spectral information. In the retina, this is implemented by ("color")opponent wiring. Beyond the requirement for some type of chromatic opponency Buchsbaum and Gottschalk (Buchsbaum \& Gottschalk 1983) pointed out that for a retina with $n$ spectral photoreceptors decorrelation is - under broad assumptions achieved by $n$ mechanisms with spectral responses such that one has no zerocrossings (i.e. responses have the same sign to all wavelengths), the second has one zero crossing (i.e. responses to short wavelengths are of the opposite sign to those to long wavelengths) and the third has two zero-crossings (i.e. responses to medium wavelengths of the opposite sign to those to short and long wavelengths), and so forth. It follows that mechanisms which simply transmit the outputs of a single cone types independently, or multiple signals that have the same number of zero crossings (e.g. $B+G$ vs. $R$, or $G$ vs $R$ ) are likely to be partly redundant.

\section{Part 2: Retinal circuits for color vision.}

For photoreceptors we have strong basis for understanding the function and diversity of animal color vision. Behavioural studies show also that the 'second stage' of color processing, involving retinal circuits, is both necessary and sufficient to preserve the spectral information in the photoreceptors, and that there are distinct chromatic and achromatic/luminance mechanisms (e.g. (Vorobyev \& Osorio 1998)), but reveal little about specific chromatic mechanisms. To understand how spectral information is used within the retina and beyond research is now combining single synapseresolution anatomy with direct physiological study. Key questions are: (i) what is the number and nature of opponent mechanisms that compare the outputs of different spectral receptor types, (ii) how is chromatic- and luminance-information 
represented, (iii) how do retinal mechanisms contribute to color constancy, an finally (iv) to what extent do different receptor types contribute to distinct retinal pathways. We will now look at the picture that is emerging from this work.

\section{Color opponency in the outer retina}

In general, opponency refers to a neural computation that compares the activity in sets of neurons with different tuning to a given stimulus parameter - for example spatial location or wavelength of sound or of light. For color vision, since a single detector cannot differentiate a shift in wavelength from a change in intensity, retinal color or chromatic opponency requires a comparison between at least two spectral receptor types (Hurvich \& Jameson 1957, Krauskopf et al. 1982).

In the vertebrate retina color-opponency typically begins through interactions between the photoreceptors themselves, where inhibitory connections are mediated by horizontal cells (Chapot et al. 2017b, Perlman et al. 2009). These large and highly interconnected outer retinal neurons communicate bidirectionally with photoreceptor synapses, which are known as pedicles. Typically, glutamate release from a photoreceptor's pedicle depolarises the horizontal cell, which by a variety of mechanisms then negatively feeds back onto the same pedicle (feedback) as well as to the pedicles of other cones (feedforward) (Thoreson et al. 2008, Twig et al. 2003). Thereby, cones connected via horizontal cells inhibit each other, and since horizontal cells can be electrically coupled, to form a dense functional network (Becker et al. 1998, Cook \& Becker 1995), these interactions may occur over wide spatial scales. This general mechanism establishes color-opponent response properties already at the visual system's first synapse. Since two receptors cannot occupy the same retinal location, any form of color-opponency inevitably has a spatial component. In fact, horizontal cells not only set-up opponency in wavelength and space (lateral inhibition), but also decorrelate neural signals in time. For this, horizontal cell interactions with photoreceptors use a wide range of synaptic and other mechanisms to act over different spatial, temporal and chromatic scales (Chapot et al. 2017a, Jackman et al. 2011, Kamermans et al. 2001, Kemmler et al. 2014, Verweij et al. 1996) including a wealth of feedback mechanisms that remain confined to the level of a single pedicle. While it remains largely unclear how local and global horizontal cell interactions exist in parallel (or how switching functions might work), any purely 
458 local interactions by definition cannot transmit signals to neighbouring cones, 459 meaning that color opponency can only be built using global-scale interactions. This 460 global spectral response of a horizontal cell $(\mathrm{HC})$ type, which is readily measured

461

462 from its soma (Connaughton \& Nelson 2010, Kamermans et al. 1991), depends on the specific cone connections made (Dacheux \& Raviola 1982, Goodchild et al. 1996, Li et al. 2009) as well as the type and gain of each connection (Baden et al. 2013, Breuninger et al. 2011, Chapot et al. 2017a).

Many species, especially those with more than two spectral cone types, feature multiple types of HCs with distinct, cone-selective connectivity patterns and correspondingly complex chromatic properties (Connaughton \& Nelson 2010, Kamermans et al. 1991, Packer et al. 2010). As a result, different cone types receive different spectral-contrast surround inhibition. For example, zebrafish have at least three cone-selective and one rod-selective HCs with spectrally mono-, bi- and triphasic response properties (Meier et al. 2018) (Fig. 3c). More simply, primates use a specific HC type to set up a yellow $(R+G$ dominated) surround in blue cones (Crook et al. 2011, Neitz \& Neitz 2011, Packer et al. 2010), and rabbit use a similar circuit (Mills et al. 2014) (Fig. 3a). However, how the multitude of horizontal cell connectivity patterns and feedback functions operate to serve - or even interfere with - chromatic processing in the outer retina remains poorly understood in most vertebrate groups.

\section{Inner retina and brain projections.}

Beyond spectral opponency at the level of photoreceptors, vertebrates dedicate substantial neural resources to chromatic coding in inner retinal networks (Baden et al. 2018, Dacey 1999, Euler et al. 2014, Jacobs 2008, Neitz \& Neitz 2011). The complexity of such pathways varies depending on the animal's photoreceptor complement, but many follow common wiring principles that directly emerge from the necessity of differentially combining two or more spectral input pathways. For example, one key circuit motif takes two different "spectrally-pure" bipolar cell pathways and differentially pools their signals in a postsynaptic ganglion cell, such that one bipolar cell pathway excites the ganglion cell, while the other inhibits it (Fig. 3a) (Dacey \& Lee 1994, Mills et al. 2014). The result is a color opponent ganglion cell whose spectral tuning is driven by the tuning of the specific bipolar cell pathways 
491 that it combines. A well-studied example of such a circuit forms part of the ancient

492

493

494

495

496

497

498

499

500

501

502

503

504

505

506

507

508

509

510

511

512

513

514

515 mammalian "blue-green system" (i.e. S vs L/M cone) which is conserved across mice, guinea pigs (Yin et al. 2009), ground squirrels (Sher \& DeVries 2012) and rabbits (Mills et al. 2014) all the way to primates (Dacey \& Lee 1994). For some species, including mice, ground squirrel, rabbits, guinea pigs and various primates, key anatomical connections are known. For example, mice have only one type of chromatically pure 'blue ${ }^{\mathrm{ON}}$ ' bipolar cell dubbed Type 9 (Behrens et al. 2016, Breuninger et al. 2011), which makes specific dendritic contacts only with blue cones, thereby ensuring a blue-centre response. Mouse type 9 bipolar cells, like all mammalian On-bipolar cells, express metabotrophic glutamate receptor mGluR6 on their dendrites, which results in a sign-inversion of the blue ${ }^{\text {OFF }}$ cone signal into a blue $^{\mathrm{ON}}$ signal at the level of the bipolar cell (reviewed in (Euler et al. 2014)). Accordingly, type 9 bipolar cells provide a blue ${ }^{\mathrm{ON}}$ center response to their direct postsynaptic partners. Green OFF antagonism to this blue mechanism is provided by another type of bipolar cell, perhaps the green-cone-biased Type 1 Off bipolar cell (Behrens et al. 2016). While the specific putative retinal ganglion- and/or amacrine cells completing such a circuit remain elusive in mouse, such cells are known in rabbits, guinea pigs and primates (Dacey \& Lee 1994, Mills et al. 2014, Sher \& DeVries 2012, Yin et al. 2009). For example, in primates, the small bistratified RGC selectively collects blue ${ }^{\mathrm{ON}}$ and red/green ${ }^{\mathrm{OFF}}$ inputs from different bipolar cells across its two respective dendritic arbours in the inner plexiform layer of the retina (Calkins et al. 1998, Crook et al. 2009, Dacey \& Lee 1994, Zrenner \& Gouras 1981). Notably, some mammals such as the cone-dominated ground squirrel use at least two greencone selective BCs - an On and an Off variant ( $\mathrm{Li} \&$ DeVries 2006) - to give additional options for building color opponent ganglion cells (Fig. 3a). 
A

Mammals: Blue-green circuits

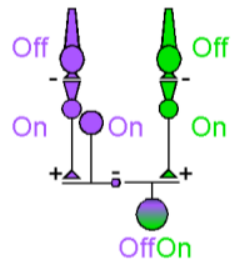

C

Zebrafish - diverse opponencies throughout

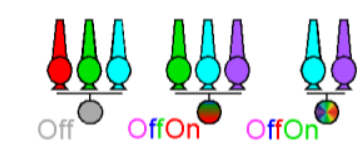

516

517

518

519

520

521

522

523

524

525

526

527

528

529

530

531

532

533

534

535

536

537

538

539

540

\section{Case studies of retinal circuits}

B

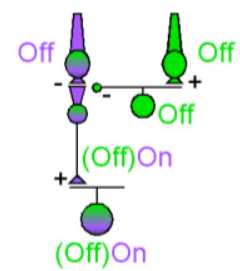

D

Primates: additional red/green - yellow circuits
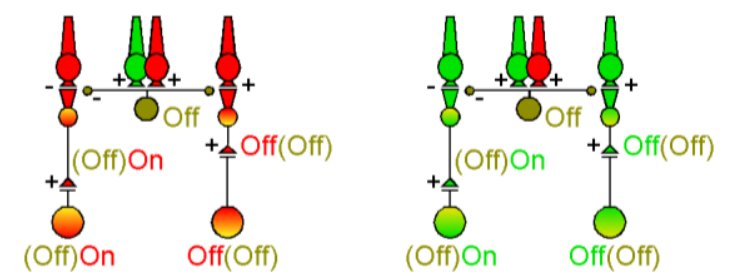

Turtle - highly diverse opponencies in RGCs

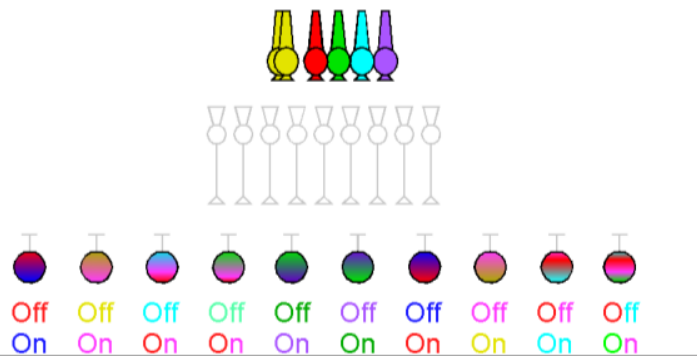

Figure 3 - Circuit Motifs for Retinal Color Opponency. A, blue-green (S-M) opponent circuits in mammals. Blue- and green-cone selective On- and Off-bipolar cells, respectively, can be differentially combined via a bistratified retinal ganglion cell (left). Similarly, sign inversion can occur via an S-On amacrine cell leading onto a monostratified retinal ganglion cell (centre). Moreover, sign inversion can occur in the outer retina via a green-dominated horizontal cell feeding into a blue-selective bipolar cell pathway (right). Reviewed in (Neitz \& Neitz 2011). B, Primates can build red-yellow (left) or green-yellow (right) opponent midget circuits by pooling a red-green non-selective surround into individual red- or green cones by way of a horizontal cell. Reviewed in (Dacey 1996, Neitz \& Neitz 2011). C, Zebrafish use at least three types of cone-selective horizontal cells to differentially poor across their tetrachromatic conecomplement. From here, retinal bipolar cells build diverse color-opponent responses at the level of their presynaptic terminals in the inner retina, and retinal ganglion cells show diverse and often complex chromatic opponencies. However, beyond photoreceptor connectivity patterns (see below) the specific functional and anatomical circuit principles that generate many of these responses are largely unknown. Reviewed in (Meier et al. 2018). D, Turtles are reported to combine their five cone-types into highly diverse retinal output channels that carry at least 12 color opponent signals to the brain (Rocha et al. 2008), but knowledge on the chromatic basis of turtle inner retinal circuits remains sparse.

The precise anatomical and functional wiring motifs for retinal color opponent circuits remain little known in all but a few species, notably primates, mice and zebrafish, each of which has specific retinal specialisations, and at times 'unusual solutions' 
541 that need to be considered when aiming to synthesise known details of their circuits 542 into a bigger picture. Here, we offer a brief introduction to some of these 543 peculiarities.

Color processing in the peculiar retina of mice

546

Like all sensory systems, the mouse retina is exquisitely adapted to the mouse's sensory-ecological niche. As a crepuscular species that spends much time underground, mice are often active in the dim light, and rods make up $>90 \%$ of all mouse photoreceptors - a proportion similar to that in primates including humans. Nonetheless, mice have a well-developed dichromatic cone system based on a UV cone $\left(\lambda_{\max } 360 \mathrm{~nm}\right)$ and an $M$ cone $\left(\lambda_{\max } 508 \mathrm{~nm}\right)$ (Nikonov et al. 2006). As in primates, long-wavelength $(\mathrm{M})$ cones outnumber short-wavelength (blue/UV) ones by over 10:1 (Wässle et al. 2009). In view of the greater abundance of green photons compared to blue/UV in natural light (Párraga et al. 1998), this makes sense, and much mouse vision uses a predominant green-driven luminance signal. The preponderance of green cones means that for color vision it is very important to build cone-selective circuits for the sparse blue system, but less important for the green system. Assuming equal gain of green and blue cone inputs (but see (Baden et al. 2013, Breuninger et al. 2011)) any randomly connecting bipolar- or horizontal cell will be green biased, simply because there are more green cones. This situation is complicated by a distinctive feature of the mouse retina: the dorso-ventral blue-green S-opsin co-expression gradient in "genetic M-cones" (Applebury et al. 2000, Baden et al. 2013, Roehlich et al. 1994, Szél et al. 1992). The ventral mouse retina, which views the sky, is dominated by $\mathrm{M}$-cones that co-express both $\mathrm{M}$ - and S-opsins. Indeed, direct spectral sensitivity recordings from ventral co-expressing presumed M-cones reveal a short wavelength bias (Baden et al. 2013, Chapot et al. 2017a), implying that that the S-opsin co-expression is dominant, converting M-cones into 'functional S-cones'. Importantly, this co-expression ceases approximately at the visual horizon, leaving the dorsal retina - looking at the ground - with 'pure' green cones, expressing the LWS opsin interspersed with 'pure' blue cones.

The opsin co-expression gradient has several functional consequences for mouse color vision. Perhaps most importantly, the standard blue-green opponent system cannot work in the ventral retina as it does in the dorsal retina. At the very least, the 
574 green signal is contaminated by enhanced blue sensitivity, and more likely the green component will be almost abolished. Given only traditional cone circuits, the ventral mouse retina would be color blind, but behavioural evidence is to the contrary (Denman et al. 2018). In fact, the mouse retina seems to use "green" rods to build opponency against the S-biased ventral M-cones (see below).

Next, an interesting type of spectral opponency arises at the boundary between the blue-dominated ventral retina and the green-dominated dorsal retina. Here large-field retinal ganglion cells that span both zones almost invariably receive a chromatically mixed input signal, which leads to centre-surround chromatic antagonism in ganglion cells near the visual horizon, without the need for any wiring specificity (Chang et al. 2013).

Overall, mice probably use a subset of the mammalian inner retinal pathways for color vision in their dorsal retina of those which have been characterized in other rodents, lagomorphs and primates. The presence of the opsin gradient markedly complicates things at the horizon and beyond but opens opportunities for exploiting chromatic contrasts by non-traditional circuit motifs. How these peculiarities translate to the brain and behaviour remains largely unclear (but see (Denman et al. 2018, Tan et al. 2015)). Notably, opsin co-expression gradients occur widely in terrestrial animals (e.g. (Sison-Mangus 2006)), and amongst mammals occur in species as diverse as hamsters and hyenas (Peichl 2005). A common feature of these seemingly disparate species is their need to survey the open sky for birds - be it for predator detection for the hamster or allowing the hyena to predict the location of prey or carrion by spotting vultures. In mice, in addition to shifting the spectral sensitivity of genetic M-cones ventral retina, S-opsin co-expression boosts the detection of achromatic dark contrasts (such as the silhouette of a bird in the sky) (Baden et al. 2013). Similar mechanisms may also be beneficial to hyenas and hamsters.

Color processing in the peculiar retina of trichromatic primates.

Next to mice, most knowledge about the retinal basis for vertebrate color vision is from trichromatic primates including humans (Dacey 1996, Neitz \& Neitz 2011). Like many reptiles and birds and some fish, primates use a specialised acute zone or fovea for high spatial-acuity vision. As with the opsin co-expression gradient in mice, 
607

608

609

610

611

612

613

614

615

616

617

618

619

620

621

622

623

624

625

626

627

628

629

630

631

632

633

634

635

636

637

638

639

the primate fovea engenders a range of behavioural and circuit peculiarities. First, since the fovea is only a degree or so across but allows much higher spatial acuity than the rest of the retina, foveated species use specialised eye-movement strategies which result in neuronal and attentional oversampling of the visual world at the fovea (Duncan \& Boynton 2003), but, S-cones are absent from the area centralis (Roorda \& Williams 1999). Consequently, any blue contribution to' chromatic contrasts at the fixation point relies on interpolation, which gives rise to a wealth of popular perceptual illusions. Outside the fovea, primates, like most mammals, have a low blue-cone density alongside a much higher green/red density (Martin \& Grunert 1999) to compute long-versus-short chromatic contrasts along a blue-yellow axis. The cone-connectivity patterns of primate bipolar cells are broadly similar to those of mice, including the presence of an S-cone selective On-bipolar cell (Boycott \& Wässle 1991, Dacey 1996), but unlike in mice, blue-yellow chromatic circuits are well-characterised for retinal ganglion cells (Calkins et al. 1998, Chichilnisky \& Baylor 1999, Dacey 1996, 2000; Neitz \& Neitz 2011). This exquisite account from primates, which is complemented by findings in a range of lagomorphs and rodents (see above) dominates the literature about short-versus-long wavelength retinal circuits in vertebrates. While this work provides a solid foundation for blue-green/yellow circuitmotifs in mammals, it is less clear to what extent this translates to non-mammalian groups.

Second, perhaps the most peculiar aspect of trichromatic primate color vision is their green (M) cone. Primate $\mathrm{M}$ cone opsin derives from an evolutionarily recent LWSopsin gene-duplication (Mollon 1989, Nathans 1999), which leads to a fundamental wiring problem. Retinal circuits cannot easily distinguish primate $L$ from $M$ cones (but see (Field et al. 2010)), and thus lack developmentally programmed red- or greenonly bipolar cell channels. Instead, chromatic selectivity depends on the presence or 'midget' bipolar- and ganglion cells (Kolb \& Marshak 2003), which receive their centre input from a single cone. The surround in turn is spectrally non-selective between red and green. This single-cone-centre wiring motif produces four types of opponent midget signals, red ${ }^{\mathrm{ON}}-$ yellow $^{\mathrm{OFF}}$, green $\mathrm{ON}_{-}$yellow $^{\mathrm{OFF}}$, yellow ${ }^{\mathrm{ON}}$-red $^{\mathrm{OFF}}$ and yellow $^{\mathrm{ON}}$-green ${ }^{\mathrm{OFF}}$ (Fig. 3b), and cone-'clumping' (Hofer et al. 2005) means that this same motif can extend beyond the foveal centre (Martin et al. 2001). However, this strategy defers the disambiguation of red and green signals to the cortex, which 
could generate chromatic selective neurons by activity dependent plasticity mechanisms (Doi et al. 2003, Wachtler et al. 2007). As such, unlike other coneopponent mechanisms, key circuits underlying our ability to distinguish "red" from "green" lie beyond the retina. Interestingly, introducing an additional red-opsin into some mouse green cones leads to apparent trichromatic vision at the behavioural level (Jacobs et al. 2007, Smallwood et al. 2003) (but see (Makous 2007).

\section{Color processing in non-mammalian vertebrates}

As we have seen, vertebrates opsins belong to for main families which evolved some 500 million years ago in jawless fish (Collin et al. 2009). Retinal circuitry probably has a similarly conservative bauplan, perhaps including chromatic opponent pathways, such as the mammalian blue ${ }^{\mathrm{ON}}$ system. However so far knowledge of this aspect of retinal processing is mainly limited to work in teleost fish - notably the cyprinids zebrafish and goldfish, and rainbow trout, e.g. (Meier et al. 2018), Fig. 3c -, reptiles (mostly turtles, Fig. 3d: (Arnold \& Neumeyer 1987, Rocha et al. 2008, Ventura et al. 2001, Zana et al. 2001)) and amphibians (Werblin \& Dowling 1969). The vast majority of this work has probed retinal function by single-cell electrophysiological techniques, which provide detail on single neurons, but have not delivered a comprehensive overview of retinal channels for color vision of any one retina. As such although there are some key studies of the retinal basis of vertebrate color vision (D'Orazi et al. 2016, Li et al. 2009), a coherent picture is yet to emerge.

Nevertheless, it is clear that species with diverse cone types such as the turtle with five cone types and the goldfish with four have a retinal complement of chromatic neurons far exceeding that of mammals - or indeed theoretical prediction (see above). For example, at least 12 color opponent retinal ganglion cells have been described in the turtle (Trachemys scripta) (Rocha et al. 2008, Ventura et al. 2001) (Fig. 3d), while teleosts including goldfish, zebrafish, carp and trout display complex chromatic responses even at the level of horizontal cells (Connaughton \& Nelson 2010, Kamermans et al. 1991, Meier et al. 2018, Twig \& Perlman 2004, Twig et al. 2003). Nonetheless, more coherent picture of the retinal basis for color vision is emerging in at least one tetrachromatic vertebrate: the zebrafish (Fig. 3c). 
672

673 Like many shallow-water teleosts, zebrafish use four ancient cone types for color 674 vision: red, green, blue and UV, which in adults form a crystalline mosaic with a 675 stoichiometry of 2:2:1:1, respectively (Allison et al., Engström 1960). Each cone type 676 is genetically distinct, allowing developmentally hardwired retinal circuits (D'Orazi et 677

\section{Color processing in the peculiar retina of zebrafish} al. 2016, Li et al. 2009) in any of 24 theoretically possible chromatic combinations (or 81 if differentiating On and Off connections). Yet, partly in line with arguments on chromatic redundancy (above), most combinations appear to not be absent. Instead, cone-selective wiring appears to be mainly restricted to spectral 'blocks' rather than 'jumps' (Fig. 4). For example, horizontal cell types make selective connections to chromatically neighbouring cones ('blocks'): $R+G+B, G+B+U$ and $B+U$ (Klaassen et al. 2016, Song et al. 2008). In contrast wiring "jumps" (e.g. to R+B but skipping $G$ ) are absent. Bipolar cells follow the same principle (Fig. 4b). For comparison, the two cone types of mice and failure to distinguish $G$ and $R$ cones in primates means that also these setups by definition must use blocks ('jumping' requires at least 3 cones) (Fig. 4a). This 'block-wiring principle' of retinal chromatic circuits is untested in any other group, but it is worth noting that on a functional level, bipolar and retinal ganglion cells of non-mammalian species tend to favour long-vs-short wavelength computations, consistent with chromatic block-wiring in the outer retina (Rocha et al. 2008, Zimmermann et al. 2018).

A Mouse

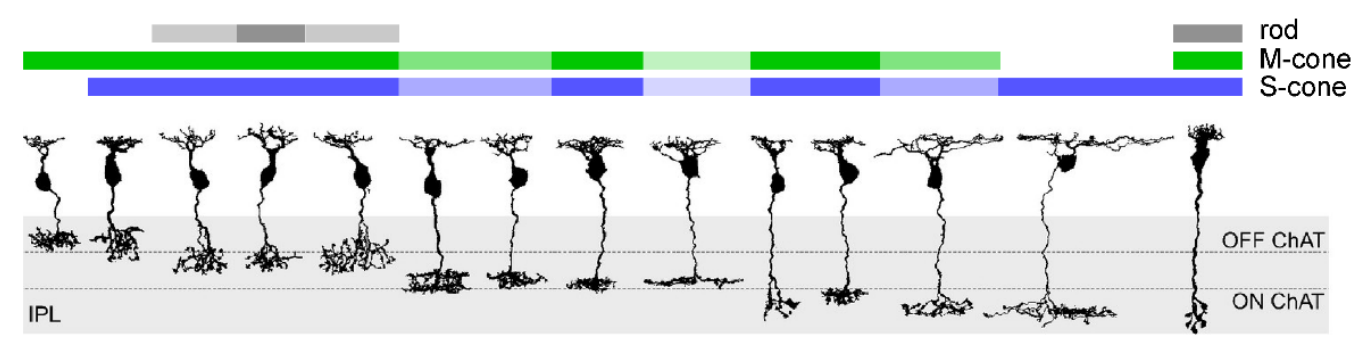

B Zebrafish (adult)
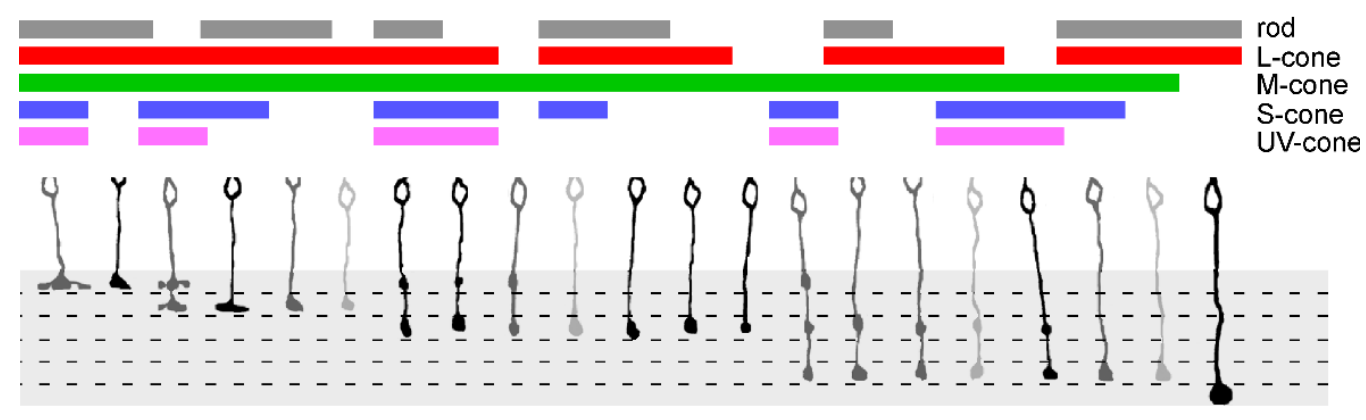
Figure 4 - Wiring photoreceptors to bipolar cells. A, The 14 types of bipolar cells of the mouse retina mostly make cone-type non-selective contacts in the outer retina. Only types 1 (leftmost) and 9 ( $2^{\text {nd }}$ from right) bipolar cells make selective contacts with $M$ - and S-cones, respectively. Rods are contacted by a subset of Off-bipolar cells and rod bipolar cells. Modified from (Behrens et al. 2016). B, Adult zebrafish have 20+ bipolar cells that make diverse sets of contacts across its four cone- and one rod type in the outer retina. Based on (Li et al. 2009).

Simply knowing the anatomical wiring is however insufficient for defining chromatic circuits: After all, opponency requires the combination of differentially tuned pathways with opposite signs, which are difficult to identify from anatomy alone. Here, some understanding of the chromatic physiology of the zebrafish retina is beginning to emerge. Single unit electrophysiological recordings from throughout the zebrafish retina from horizontal cells to ganglion cells, all reveal a rich complement of chromatic opponencies (Connaughton \& Nelson 2010, 2015; Klaassen et al. 2016, Torvund et al. 2017).

\section{Regional specialisations in juvenile zebrafish retina}

Even if retinal circuits for color vision of the adult zebrafish are reasonably typical of teleosts of similar habitat and lifestyle, whether the same circuitry is present in the larva remains unknown. Building on the wealth of single-cell physiology from both adults and larvae, a recent survey used 2-photon calcium imaging to record the chromatic response properties of some 4,000 larval zebrafish bipolar cells (Zimmermann et al. 2018). Eight-day post fertilization zebrafish larvae have about 10,000 cones in each retina, and single-synapse resolution functional measurements can be made in vivo, in any part of the eye. The survey revealed that chromatic processing in the inner retina of larval zebrafish is not only very rich indeed, but perhaps more intriguingly, differs dramatically across the visual field. For example, at the visual horizon bipolar cells encode several varieties of mostly short-vs-long wavelength chromatic opponency while the temporo-ventral retina that views the world just above the horizon in front of the animal, was dominated by UVON responses despite the presence of all cone-types in this part of the eye. In addition, ventral visual circuits, which survey the sky through Snell's window, were all but color-blind, probably because there is little chromatic information here. This forms an 
727 interesting parallel with the mouse, where cone-only dichromacy also disappears above the horizon.

Where present, in larval zebrafish bipolar cells encoding color opponent or chromatically biased physiologies are systematically distributed into specific layers of the inner retina. For example, layers 1 and 3 of the dorsal retina were dominated by $\mathrm{RG}$ vs $\mathrm{BU}$ and $\mathrm{R}$ vs $\mathrm{GBU}$ color opponent responses. Accordingly, retinal ganglion cells that project specifically to these layers should inherit a similar physiology (Connaughton \& Nelson 2015, Meier et al. 2018), thus leading to color opponent brain projections that are established already at the second synapse of the visual system. This is corroborated by bipolar recordings in other non-mammalian retinas: mudpuppies, turtles, goldfish and giant danio (Devario aequipinnatus) all have fully color opponent bipolar cells (Stell 1978, Werblin \& Dowling 1969, Wong \& Dowling 2005, Yazulla 1976). Clearly much color opponency is already present at the level of the input to retinal ganglion cells.

\section{Rod-based color vision}

Rods are generally inactive at high (photopic) light levels, but in mesopic conditions, when both rod and cone systems are simultaneously active, rod-cone chromatic antagonism can occur. This co-activity regime of rods and cones may extend to traditionally photopic levels (Szikra et al. 2014, Tikidji-Hamburyan et al. 2015). Vertebrate rods express $\mathrm{RH} 1$ rhodopsin, which in most species is spectrally similar to green cones. Accordingly, rod-driven networks can provide green antagonism. In the ventral mouse retina, this system appears to be exploited by at least one type of retinal ganglion cell (Joesch \& Meister 2016), and it seems likely that further circuits in both mice and other species use rod signals (Baden et al. 2016, Field et al. 2009, Reitner et al. 1991). Rod-cone opponency might support some form of color vision in cone-monochromats such as most sharks, marine mammals and or racoons (Griebel \& Peichl 2003, Oppermann et al. 2016, Peichl 2005, Von Schantz et al. 1997). However, since most cone-monochromats use green cones which overlap strongly in spectral sensitivity with rods, it remains unclear how much chromatic contrast might be available. Beyond building rod-cone opponent networks, some species even feature two types of spectrally distinct rods, and there is evidence for rod-rod 
759 opponency allowing color vision at low light levels (Denton \& Wyllie 1955, Hailman 760 1976, Korenyak \& Govardovskii 2013, Yovanovich et al. 2017).

761

762

763

Acknowledgements

764 We thank Thomas Euler and Leo Peichl for very helpful discussions. The authors 765 would also like to acknowledge support from the FENS-Kavli Network of Excellence 766 and from the EMBO-YIP network.

767

768 Funding

769 Funding was provided by the European Research Council (ERC-StG "NeuroVisEco" 770 677687), UKRI (BBSRC, BB/R014817/1 and MRC, MC_PC_15071), The

771 Leverhulme Trust (PLP-2017-005) and The Lister Institute for Preventive Medicine. 
773

774

775

776

777

778

779

780

781

782

783

784

785

786

787

788

789

790

791

792

793

794

795

796

\section{REFERENCES}

Allison WT, Barthel LK, Skebo KM, Takechi M, Kawamura S, Raymond PA.

Ontogeny of cone photoreceptor mosaics in zebrafish. J. Comp. Neurol. 518(20):4182-95

Applebury M., Antoch M., Baxter L., Chun LL., Falk J., et al. 2000. The Murine Cone Photoreceptor: A Single Cone Type Expresses Both S and M Opsins with Retinal Spatial Patterning. Neuron. 27(3):513-23

Appudurai AM, Hart NS, Zurr I, Collin SP. 2016. Morphology, Characterization and Distribution of Retinal Photoreceptors in the South American (Lepidosiren paradoxa) and Spotted African (Protopterus dolloi) Lungfishes. Front. Ecol. Evol.

Arnold K, Neumeyer C. 1987. Wavelength discrimination in the turtle Pseudemys scripta elegans. Vision Res.

Arshavsky VY, Lamb TD, Pugh EN. 2002. G proteins and phototransduction. Annu. Rev. Physiol. 64:153-87

Atick JJ, Li Z, Redlich AN. 1992. Understanding Retinal Color Coding from First Principles. Neural Comput.

Autrum H, Zwehl V v. 1964. Die spektrale Empfindlichkeit einzelner Sehzellen des Bienenauges. Zeitschrift f??r Vergleichende Physiol.

Baddeley RJ, Osorio D, Jones CD. 2007. Generalization of Color by Chickens: Experimental Observations and a Bayesian Model. Am. Nat.

Baden T, Berens P, Franke K, Román Rosón M, Bethge M, Euler T. 2016. The functional diversity of retinal ganglion cells in the mouse. Nature. 529(7586):345-50

Baden T, Schubert T, Berens P, Euler T. 2018. The Functional Organization of 
797

798

799

800

801

802

803

804

805

806

807

808

809

810

811

812

Vertebrate Retinal Circuits for Vision. Oxford Res. Encycl. Neurosci.

Baden T, Schubert T, Chang L, Wei T, Zaichuk M, et al. 2013. A tale of two retinal domains: near-optimal sampling of achromatic contrasts in natural scenes through asymmetric photoreceptor distribution. Neuron. 80(5):1206-17

Barlow HB. 1982. What causes trichromacy? A theoretical analysis using combfiltered spectra. Vision Res.

Barlow HBH. 1961. Possible principles underlying the transformation of sensory messages. In Sensory Communication, pp. 217-34

Becker D, Bonness V, Mobbs P. 1998. Cell Coupling in the retina: Patterns and Purpose. Cell Biol. Int. 22(11-12):781-92

Behrens C, Schubert T, Haverkamp S, Euler T, Berens P, et al. 2016. Connectivity map of bipolar cells and photoreceptors in the mouse retina. Elife. 5:1206-17

Bowmaker JK. 1984. Microspectrophotometry of vertebrate photoreceptors. A brief review

Bowmaker JK. 2008. Evolution of vertebrate visual pigments. Vision Res.

Bowmaker JK, Heath LA, Wilkie SE, Hunt DM. 1997. Visual pigments and oil droplets from six classes of photoreceptor in the retinas of birds. Vision Res.

Bowmaker JK, Loew ER, Ott M. 2005. The cone photoreceptors and visual pigments of chameleons. J. Comp. Physiol. A Neuroethol. Sensory, Neural, Behav. Physiol.

Boycott BB, Wässle H. 1991. Morphological classification of bipolar cells of the primate retina. Europ.J.Neurosci. 3:1069-88

Brainard DH, Stockman A. 2010. Colorimetry. In OSA Handbook of Optics (3rd Edition, M. Bass, Ed) 
821 Breuninger T, Puller C, Haverkamp S, Euler T. 2011. Chromatic bipolar cell pathways in the mouse retina. J. Neurosci. 31(17):6504-17

823

824

825

826

827

828

829

830

831

832

833

834

835

836

837

838

839

840

841

842

843

844

Buchsbaum G, Gottschalk a. 1983. Trichromacy, opponent colours coding and optimum colour information transmission in the retina. Proc. R. Soc. Lond. B. Biol. Sci. 220(1218):89-113

Calkins DJ, Tsukamoto Y, Sterling P. 1998. Microcircuitry and mosaic of a blueyellow ganglion cell in the primate retina. J. Neurosci. 18(9):3373-85

Caves EM, Green PA, Zipple MN, Peters S, Johnsen S, Nowicki S. 2018. Categorical perception of colour signals in a songbird

Champ CM, Vorobyev M, Marshall NJ. 2016. Colour thresholds in a coral reef fish. R. Soc. Open Sci.

Chang L, Breuninger T, Euler T. 2013. Chromatic Coding from Cone-type Unselective Circuits in the Mouse Retina. Neuron. 77(3):559-71

Chapot CA, Behrens C, Rogerson LE, Baden T, Pop S, et al. 2017a. Local Signals in Mouse Horizontal Cell Dendrites. Curr. Biol.

Chapot CA, Euler T, Schubert T. 2017b. How do horizontal cells 'talk' to cone photoreceptors? Different levels of complexity at the cone-horizontal cell synapse. J. Physiol. 595(16):5495-5506

Cheney KL, Newport C, McClure EC, Marshall NJ. 2013. Colour vision and response bias in a coral reef fish. J. Exp. Biol.

Chichilnisky EJ, Baylor D a. 1999. Receptive-field microstructure of blue-yellow ganglion cells in primate retina. Nat. Neurosci. 2(10):889-93

Chinen A, Hamaoka T, Yamada Y, Kawamura S. 2003. Gene duplication and spectral diversification of cone visual pigments of zebrafish. Genetics. 

$163(2): 663-75$

846 Chittka L, Faruq S, Skorupski P, Werner A. 2014. Colour constancy in insects 847 Clarke GL. 1936. On the Depth at Which Fish Can See. Ecology. 17(3):452-56 848 Collin SP, Davies WL, Hart NS, Hunt DM. 2009. The evolution of early vertebrate photoreceptors. Philos. Trans. R. Soc. B Biol. Sci. 364(1531):2925-40

850

851

852

Connaughton VP, Nelson R. 2010. Spectral Responses in Zebrafish Horizontal Cells Include a Tetraphasic Response and a Novel UV-Dominated Triphasic Response. J. Neurophysiol. 104(5):2407-22

Connaughton VP, Nelson R. 2015. Ultraviolet dominates ganglion cell responses in larval zebrafish. Invest. Ophthalmol. Vis. Sci, p. 3251

Cook JE, Becker DL. 1995. Gap junctions in the vertebrate retina [review]. Microsc. Res. Tech. 31(5):408-19

Cronin H. 1991. The Ant and the Peacock. In The Ant and the Peacock: Altruism and Sexual Selection from Darwin to Today

Crook JD, Davenport CM, Peterson BB, Packer OS, Detwiler PB, Dacey DM. 2009. Parallel ON and OFF cone bipolar inputs establish spatially coextensive receptive field structure of blue-yellow ganglion cells in primate retina. $\mathrm{J}$. Neurosci. 29(26):8372-87

Crook JD, Manookin MB, Packer OS, Dacey DM. 2011. Horizontal cell feedback without cone type-selective inhibition mediates "red-green" color opponency in midget ganglion cells of the primate retina. J. Neurosci. 31(5):1762-72

D'Orazi FD, Zhao XF, Wong RO, Yoshimatsu T. 2016. Mismatch of Synaptic Patterns between Neurons Produced in Regeneration and during Development of the Vertebrate Retina. Curr. Biol. 26(17):2268-79 
869 Dacey DM. 1996. Circuitry for color coding in the primate retina. Proc.R.Soc.Lond.B.

870 93(2):582-88

871

Dacey DM. 1999. Primate retina: cell types, circuits and color opponency. Prog.

872 Retin. Eye Res. 18(6):737-63

873

Dacey DM. 2000. Parallel pathways for spectral coding in primate retina. Annu. Rev. Neurosci. 23:743-75

875

876

877

878

879

880

881

882

883

884

885

886

887

888

889

890

891

892

Dacey DM, Lee BB. 1994. The "blue-on" opponent pathway in primate retina originates from a distinct bistratified ganglion cell type. Nature. 367(6465):73135

Dacheux RF, Raviola E. 1982. Horizontal cells in the retina of the rabbit. J. Neurosci. 2(10):1486-93

Dalton BE, Loew ER, Cronin TW, Carleton KL. 2014. Spectral tuning by opsin coexpression in retinal regions that view different parts of the visual field. Proc. R. Soc. B Biol. Sci. 281(1797):20141980-20141980

Darwin C. 1859. On the Origin of Species by Means of Natural Selection

Davies WIL, Collin SP, Hunt DM. 2012. Molecular ecology and adaptation of visual photopigments in craniates

Denman DJ, Luviano JA, Ollerenshaw DR, Cross S, Williams D, et al. 2018. Mouse color and wavelength-specific luminance contrast sensitivity are non-uniform across visual space. Elife. 7:

Denton EJ, Wyllie JH. 1955. Study of the photosensitive pigments in the pink and green rods of the frog. J. Physiol. 127(1):81-89

Derrington AM, Krauskopf J, Lennie P. 1984. Chromatic mechanisms in lateral geniculate nucleus of macaque. J. Physiol. 
893 Doi E, Inui T, Lee TW, Wachtier T, Sejnowski TJ. 2003. Spatiochromatic receptive 894 field properties derived from information-theoretic analyses of cone mosaic 895 responses to natural scenes. Neural Comput.

896

Dörr S, Neumeyer C. 2000. Color constancy in goldfish: The limits. J. Comp. Physiol.

897 - A Sensory, Neural, Behav. Physiol.

898

Duncan RO, Boynton GM. 2003. Cortical Magnification within Human Primary Visual 899 Cortex Correlates with Acuity Thresholds. Neuron. 38(4):659-71

900

Engström K. 1960. Cone types and cone arrangements in the retina of some

901 cyprinids. Acta Zool. 41:277-295

902

Engström K. 1963. Cone types and cone arrangements in teleost retinae

903

904

905

906

907

908

909

910

911

912

913

914

915

916

Enright JM, Toomey MB, Sato SY, Temple SE, Allen JR, et al. 2015. Cyp27c1 redshifts the spectral sensitivity of photoreceptors by converting Vitamin A1 into A2. Curr. Biol. 25(23):3048-57

Euler T, Haverkamp S, Schubert T, Baden T. 2014. Retinal bipolar cells: Elementary building blocks of vision. Nat. Rev. Neurosci. 15(8):

Field GD, Gauthier JL, Sher A, Greschner M, Machado TA, et al. 2010. Functional connectivity in the retina at the resolution of photoreceptors. Nature. 467(7316):673-77

Field GD, Greschner M, Gauthier JL, Rangel C, Shlens J, et al. 2009. Highsensitivity rod photoreceptor input to the blue-yellow color opponent pathway in macaque retina. Nat. Neurosci. 12(9):1159-64

Gegenfurtner KR, Kiper DC. 2003. C <scp>OLOR</scp $>$ V <scp $>$ ISION</scp $>$. Annu. Rev. Neurosci.

Goldsmith TH, Butler BK. 2003. The roles of receptor noise and cone oil droplets in 

the photopic spectral sensitivity of the budgerigar, Melopsittacus undulatus. $J$. Comp. Physiol. A

Goodchild AK, Chan TL, Grünert U. 1996. Horizontal cell connections with shortwavelength-sensitive cones in macaque monkey retina. Vis. Neurosci. 13(5):833-45

Govardovskii VI, Fyhrquist N, Reuter T, Kuzmin DG, Donner K. 2000. In search of the visual pigment template. Vis. Neurosci.

Griebel U. 2002. Color Vision in Marine Mammals: A Review. In The Vienna School of Marine Biology: A Tribute to Jörg Ott

Griebel U, Peichl L. 2003. Colour vision in aquatic mammals_facts and open questions. Aquat. Mamm. 291:18-30

Hailman JP. 1976. Oildroplets in the eyes of adult anuran amphibians: A comparative survey. J. Morphol. 148(4):453-68

Hart NS. 2001. The visual ecology of avian photoreceptors

Hart NS, Hunt DM. 2007. Avian Visual Pigments: Characteristics, Spectral Tuning, and Evolution. Am. Nat.

Hart NS, Vorobyev M. 2005. Modelling oil droplet absorption spectra and spectral sensitivities of bird cone photoreceptors. J. Comp. Physiol. A Neuroethol. Sensory, Neural, Behav. Physiol.

Hofer H, Carroll J, Neitz J, Neitz M, Williams DR. 2005. Organization of the Human Trichromatic Cone Mosaic. J. Neurosci. 25(42):9669-79

Hurvich LM, Jameson D. 1957. An opponent-process theory of color vision. Psychol. Rev. 64, Part 1(6):384-404

Jackman SL, Babai N, Chambers JJ, Thoreson WB, Kramer RH. 2011. A Positive 
Feedback Synapse from Retinal Horizontal Cells to Cone Photoreceptors. PLoS

Jacobs G. 1981. Comparative Color Vision. Academic Press

944 Jacobs G. 2008. Primate color vision: a comparative perspective. Vis. Neurosci.

Jacobs G, Williams G, Cahill H, Nathans J. 2007. Emergence of novel color vision in mice engineered to express a human cone photopigment. Science (80-. ).

Jiao Y, Lau T, Hatzikirou H, Meyer-Hermann M, Corbo JC, Torquato S. 2014. Avian photoreceptor patterns represent a disordered hyperuniform solution to a multiscale packing problem. Phys. Rev. E - Stat. Nonlinear, Soft Matter Phys.

950

951

952

953

954

955

956

957

958

959

960

961

962

963

964

Joesch M, Meister M. 2016. A neuronal circuit for colour vision based on rod-cone opponency. Nature. 532(7598):236-39

Jones CD, Osorio D. 2004. Discrimination of oriented visual textures by poultry chicks. Vision Res.

Jones CD, Osorio D, Baddeley RJ. 2001. Colour categorization by domestic chicks. Proc. R. Soc. B Biol. Sci.

Kamermans M, Fahrenfort I, Schultz K, Janssen-Bienhold U, Sjoerdsma T, Weiler R. 2001. Hemichannel-mediated inhibition in the outer retina. Science (80-. ).

Kamermans M, van Dijk BW, Spekreijse H. 1991. Color opponency in cone-driven horizontal cells in carp retina. Aspecific pathways between cones and horizontal cells. J. Gen. Physiol. 97(4):819-43

Kelber A, Osorio D. 2010. From spectral information to animal colour vision: Experiments and concepts. Proc. R. Soc. B Biol. Sci.

Kelber A, Vorobyev M, Osorio D. 2003. Animal colour vision - Behavioural tests and physiological concepts 
965 Kemmler R, Schultz K, Dedek K, Euler T, Schubert T. 2014. Differential regulation of

966

967

968

969

970

971

972

973

974

975

976

977

978

979

980

981

982

983

984

985

986

987 cone calcium signals by different horizontal cell feedback mechanisms in the mouse retina. J. Neurosci. 34(35):11826-43

Klaassen LJ, de Graaff W, van Asselt JB, Klooster J, Kamermans M. 2016. Specific connectivity between photoreceptors and horizontal cells in the zebrafish retina. J. Neurophysiol. 116(6):2799-2814

Kolb H, Marshak D. 2003. The midget pathways of the primate retina. Doc. Ophthalmol. 106(1):67-81

Korenyak DA, Govardovskii VI. 2013. Photoreceptors and visual pigments in three species of newts. J. Evol. Biochem. Physiol. 49(4):399-407

Kram YA, Mantey S, Corbo JC, Hart N, Bowmaker J, et al. 2010. Avian cone photoreceptors tile the retina as five independent, self-organizing mosaics. PLoS One. 5(2):e8992

Krauskopf J, Williams DR, Heeley DW. 1982. Cardinal directions of color space. Vision Res. 22(9):1123-31

Lamb TD. 2013. Evolution of phototransduction, vertebrate photoreceptors and retina

Lee BB, Cooper B, Cao D. 2017. The spatial structure of cone-opponent receptive fields in macaque retina. Vision Res.

Lee BB, Pokorny J, Smith VC, Martin PR, Valberg a. 1990. Luminance and chromatic modulation sensitivity of macaque ganglion cells and human observers. J. Opt. Soc. Am. Opt. Image Sci. Vis.

Li W, DeVries SH. 2006. Bipolar cell pathways for color and luminance vision in a dichromatic mammalian retina. Nat. Neurosci. 9(5):669-75 
989

990

991

992

993

994

995

996

997

998

999

1000

1001

1002

1003

1004

1005

1006

1007

1008

1009

1010

1011

1012

Li YN, Matsui JI, Dowling JE. 2009. Specificity of the horizontal cell-photoreceptor connections in the zebrafish (Danio rerio) retina. J. Comp. Neurol. 516(5):44253

Lind O, Henze MJ, Kelber A, Osorio D. 2017. Coevolution of coloration and colour vision? Philos. Trans. R. Soc. B Biol. Sci.

Livingstone M, Hubel D. 1988. Segregation of form, color, movement, and depth: Anatomy, physiology, and perception. Science (80-. ).

Loew ER, Dartnall HJA. 1976. Vitamin A1/A2-based visual pigment mixtures in cones of the rudd. Vision Res. 16(9):891-96

Loew ER, Fleishman LJ, Foster RG, Provencio I. 2002. Visual pigments and oil droplets in diurnal lizards: A comparative study of Caribbean anoles. J. Exp. Biol.

Loew ER, Lythgoe JN. 1985. The ecology of colour vision. Endeavour

Lubbock J. 1882. Ants, Bees and Wasps. A Record of Observations on the Habits of the Social Hymenoptera

Lubbock SJ. 1889. On the Senses, Instincts, and Intelligence of Animals, with Special Reference to Insects. 292 Pages, 118 Figures. London: Kegan Paul, Trench. London, UK: Kegan Paul

Luk HL, Bhattacharyya N, Montisci F, Morrow JM, Melaccio F, et al. 2016. Modulation of thermal noise and spectral sensitivity in Lake Baikal cottoid fish rhodopsins. Sci. Rep.

Makous W. 2007. Comment on \&quot;Emergence of Novel Color Vision in Mice Engineered to Express a Human Cone Photopigment\&quot; Science (80-. ). 318(5848):196b-196b 
1013 Maloney LT. 1986. Evaluation of linear models of surface spectral reflectance with 1014 small numbers of parameters. J. Opt. Soc. Am. A

1015

1016

1017

1018

1019

1020

1021

1022

1023

1024

1025

1026

1027

1028

1029

1030

1031

1032

1033

1034

1035

1036

Martin PR, Grunert U. 1999. Analysis of the short wavelength-sensitive ("blue") cone mosaic in the primate retina: Comparison of New World and Old World monkeys. J. Comp. Neurol. 406(1):1-14

Martin PR, Lee BB, White AJR, Solomon SG, Rüttiger L. 2001. Chromatic sensitivity of ganglion cells in the peripheral primate retina. Nature. 410(6831):933-36

Meier A, Nelson R, Connaughton VP. 2018. Color Processing in Zebrafish Retina. Front. Cell. Neurosci.

Meredith RW, Gatesy J, Emerling CA, York VM, Springer MS. 2013. Rod Monochromacy and the Coevolution of Cetacean Retinal Opsins. PLoS Genet. 9(4):e1003432

Mills SL, Tian L-M, Hoshi H, Whitaker CM, Massey SC. 2014. Three distinct bluegreen color pathways in a mammalian retina. J. Neurosci. 34(5):1760-68

Mollon JD. 1989. "Tho" she kneel'd in that plaace where they grew...' . J. Exp. Biol.

Mollon JD. 2003. Introduction: Thomas Young and the Trichromatic Theory of Colour Vision. In Normal and Defective Colour Vision. Oxord University Press

Mullen KT, Losada M a. 1994. Evidence for separate pathways for color and luminance detection mechanisms. J. Opt. Soc. Am. A

Nathans J. 1999. The Evolution and Physiology of Human Review Color Vision: Insights from Molecular Genetic Studies of Visual Pigments. Neuron. 24:299312

Nathans J, Thomas D, Hogness D. 1986. Molecular genetics of human color vision: the genes encoding blue, green, and red pigments. Science (80-. ). 
1037 Neitz J, Neitz M. 2011. The genetics of normal and defective color vision. Vision Res. 51(7):633-51

1039

Neumeyer C. 1986. Wavelength discrimination in the goldfish. J. Comp. Physiol. A

1040 Neumeyer C. 1992. Tetrachromatic color vision in goldfish: evidence from color mixture experiments. J. Comp. Physiol. A

Neumeyer C, Arnold K. 1989. Tetrachromatic color vision in the goldfish becomes trichromatic under white adaptation light of moderate intensity. Vision Res.

Nikonov SS, Kholodenko R, Lem J, Pugh EN. 2006. Physiological Features of the Sand M-cone Photoreceptors of Wild-type Mice from Single-cell Recordings. J. Gen. Physiol. 127(4):359-74

1047

Ödeen A, Håstad O. 2003. Complex distribution of avian color vision systems revealed by sequencing the SWS1 opsin from total DNA. Mol. Biol. Evol.

Okano T, Yoshizawa T, Fukada Y. 1994. Pinopsin is a chicken pineal photoreceptive 1050 molecule. Nature

Olsson P, Lind O, Kelber A. 2015. Bird colour vision: behavioural thresholds reveal receptor noise. J. Exp. Biol.

Olsson P, Lind O, Kelber A. 2018. Chromatic and achromatic vision: Parameter choice and limitations for reliable model predictions

Olsson P, Wilby D, Kelber A. 2016. Quantitative studies of animal colour constancy: Using the chicken as model. Proc. R. Soc. B Biol. Sci.

Oppermann D, Schramme J, Neumeyer C. 2016. Rod-cone based color vision in seals under photopic conditions. Vision Res.

Orger MB, Baier H. 2005. Channeling of red and green cone inputs to the zebrafish optomotor response. Vis. Neurosci. 22(3):275-81 
1061 Osorio D, Ham a D. 2002. Spectral reflectance and directional properties of

1062 structural coloration in bird plumage. J. Experimantal Biol.

1063

1064

1065

1066

1067

1068

1069

1070

1071

1072

1073

1074

1075

1076

1077

1078

1079

1080

1081

1082

1083

1084

Osorio D, Ruderman DL, Cronin TW. 1998. Estimation of errors in luminance signals encoded by primate retina resulting from sampling of natural images with red and green cones. J. Opt. Soc. Am. a-Optics Image Sci. Vis. 15(1):16-22

Osorio D, Vorobyev M. 1996. Colour vision as an adaptation to frugivory in primates. Proc. R. Soc. B Biol. Sci.

Osorio D, Vorobyev M. 2008. A review of the evolution of animal colour vision and visual communication signals. Vision Res.

Osorio D, Vorobyev M, Jones CD. 1999. Colour vision in domestic chicks. J. Exp. Biol.

Packer OS, Verweij J, Li PH, Schnapf JL, Dacey DM. 2010. Blue-yellow opponency in primate S cone photoreceptors. J. Neurosci. 30(2):568-72

Palacios AG, Varela FJ, Srivastava R, Goldsmith TH. 1998. Spectral sensitivity of cones in the goldfish, Carassius auratus. Vision Res.

Párraga C a, Brelstaff G, Troscianko T, Moorehead IR. 1998. Color and luminance information in natural scenes. J. Opt. Soc. Am. A. Opt. Image Sci. Vis. 15(3):563-69

Parry JWL, Carleton KL, Spady T, Carboo A, Hunt DM, Bowmaker JK. 2005. Mix and match color vision: Tuning spectral sensitivity by differential opsin gene expression in Lake Malawi cichlids. Curr. Biol.

Patel JS, Brown CJ, Ytreberg FM, Stenkamp DL. 2018. Predicting peak spectral sensitivities of vertebrate cone visual pigments using atomistic molecular simulations. PLoS Comput. Biol. 
1085 Peichl L. 2005. Diversity of mammalian photoreceptor properties: adaptations to 1086 habitat and lifestyle? Anat. Rec. A. Discov. Mol. Cell. Evol. Biol. 287(1):1001-12

1087

1088

1089

1090

1091

1092

1093

1094

1095

1096

1097

1098

1099

1100

1101

1102

1103

1104

1105

1106

1107

1108 43

Pignatelli V, Champ C, Marshall J, Vorobyev M. 2010. Double cones are used for colour discrimination in the reef fish, rhinecanthus aculeatus. Biol. Lett.

Porter ML, Cronin TW, McClellan DA, Crandall KA. 2007. Molecular characterization of crustacean visual pigments and the evolution of pancrustacean opsins. Mol. Biol. Evol.

Potier S, Mitkus M, Kelber A. 2018. High resolution of colour vision, but low contrast sensitivity in a diurnal raptor. Proc. $R$. Soc. London B Biol. Sci.

Prum RO. 2012. Aesthetic evolution by mate choice: Darwin's really dangerous idea

Raymond PA, Barthel LK, Rounsifer ME, Sullivan SA, Knight JK. 1993. Expression of rod and cone visual pigments in goldfish and zebrafish: A rhodopsin-like gene is expressed in cones. Neuron

Reitner A, Sharpe LT, Zrenner E. 1991. Is colour vision possible with only rods and blue-sensitive cones?

Remy M, Emmerton J. 1989. Behavioral Spectral Sensitivities of Different Retinal Areas in Pigeons. Behav. Neurosci.

Rister J, Desplan C. 2011. The retinal mosaics of opsin expression in invertebrates and vertebrates

Rocha FAF, Saito CA, Silveira LCL, De Souza JM, Ventura DF. 2008. Twelve chromatically opponent ganglion cell types in turtle retina. Vis. Neurosci. 25(3):307-15 
1109 Roehlich P, Van Veen T, Szél A. 1994. Two different visual pigments in one retinal cone cell. Neuron. 13(5):1159-66

1111

Roorda a, Williams DR. 1999. The arrangement of the three cone classes in the living human eye. Nature. 397(6719):520-22

Shand J, Davies WL, Thomas N, Balmer L, Cowing JA, et al. 2008. The influence of ontogeny and light environment on the expression of visual pigment opsins in the retina of the black bream, Acanthopagrus butcheri. J. Exp. Biol.

Sher A, DeVries SH. 2012. A non-canonical pathway for mammalian blue-green color vision. Nat. Neurosci. 15(7):952-53

Siebeck UE, Marshall NJ. 2001. Ocular media transmission of coral reef fish--can coral reef fish see ultraviolet light? Vision Res. 41(2):133-49

Simoncelli EP, Olshausen BA. 2001. Natural image statistics and neural representation. Annu Rev Neurosci. 24:1193-1216

Sison-Mangus MP. 2006. Beauty in the eye of the beholder: the two blue opsins of lycaenid butterflies and the opsin gene-driven evolution of sexually dimorphic eyes. J. Exp. Biol.

Smallwood PM, Olveczky BP, Williams GL, Jacobs GH, Reese BE, et al. 2003. Genetically engineered mice with an additional class of cone photoreceptors: Implications for the evolution of color vision. Proc. Natl. Acad. Sci.

$$
\text { 100(20):11706-11 }
$$

Song PI, Matsui JI, Dowling JE. 2008. Morphological types and connectivity of horizontal cells found in the adult zebrafish (Danio rerio) retina. J. Comp. Neurol. 506(2):328-38

Spady TC, Parry JWL, Robinson PR, Hunt DM, Bowmaker JK, Carleton KL. 2006. 
1133

1134

1135

1136

1137

1138

1139

1140

1141

1142

1143

1144

1145

1146

1147

1148

1149

1150

1151

1152

1153

1154

1155

1156

Evolution of the cichlid visual palette through ontogenetic subfunctionalization of the opsin gene arrays. Mol. Biol. Evol.

Srinivasan M V., Laughlin SB, Dubs A. 1982. Predictive coding: A fresh view of inhibition in the retina. Proc. R. Soc. London - Biol. Sci.

Stell WK. 1978. Inputs to bipolar cell dendrites in goldfish retina. Sens. Processes. 2(4):339-49

Szél A, Röhlich P, Caffé AR, Juliusson B, Aguirre G, Van Veen T. 1992. Unique topographic separation of two spectral classes of cones in the mouse retina. J. Comp. Neurol. 325(3):327-42

Szikra T, Trenholm S, Drinnenberg A, Jüttner J, Raics Z, et al. 2014. Rods in daylight act as relay cells for cone-driven horizontal cell-mediated surround inhibition. Nat. Neurosci. 17(12):1728-35

Tan Z, Sun W, Chen T-W, Kim D, Ji N. 2015. Neuronal Representation of Ultraviolet Visual Stimuli in Mouse Primary Visual Cortex. Sci. Rep. 5(1):12597

Theiss SM, Davies WIL, Collin SP, Hunt DM, Hart NS. 2012. Cone monochromacy and visual pigment spectral tuning in wobbegong sharks. Biol. Lett. 8(6):101922

Thoreson WB, Babai N, Bartoletti TM. 2008. Feedback from horizontal cells to rod photoreceptors in vertebrate retina. J. Neurosci. 28(22):5691-95

Tikidji-Hamburyan A, Reinhard K, Seitter H, Hovhannisyan A, Procyk CA, et al. 2015. Retinal output changes qualitatively with every change in ambient illuminance. Nat. Neurosci. 18(1):66-74

Toomey MB, Collins AM, Frederiksen R, Cornwall MC, Timlin JA, Corbo JC. 2015. A complex carotenoid palette tunes avian colour vision. J. R. Soc. Interface 
1157 Toomey MB, Lind O, Frederiksen R, Curley RW, Riedl KM, et al. 2016.

1158 Complementary shifts in photoreceptor spectral tuning unlock the full adaptive potential of ultraviolet vision in birds. Elife. 5(2016JULY):1-27

Torvund MM, Ma TS, Connaughton VP, Ono F, Nelson RF. 2017. Cone signals in monostratified and bistratified amacrine cells of adult zebrafish retina. J. Comp. Neurol. 525(7):1532-57

Twig G, Levy H, Perlman I. 2003. Color opponency in horizontal cells of the vertebrate retina

Twig G, Perlman I. 2004. Homogeneity and diversity of color-opponent horizontal cells in the turtle retina: Consequences for potential wavelength discrimination. J. Vis.

Ventura DF, Zana Y, Souza JM de, DeVoe RD. 2001. Ultraviolet colour opponency in the turtle retina. J. Exp. Biol. 204(14):

Verweij J, Kamermans M, Spekreijse H. 1996. Horizontal cells feed back to cones by shifting the cone calciu,-current activation range. Vision Res. 36(24):3943-53

Von Schantz M, Argamaso-Hernan SM, Szél Á, Foster RG. 1997. Photopigments and photoentrainment in the Syrian golden hamster. Brain Res. 770(1-2):13138

1175 Vorobyev M, Gumbert A, Kunze J, Giurfa M, Menzel R. 1997. Flowers through insect eyes. Isr. J. Plant Sci.

1177 Vorobyev M, Osorio D. 1998. Receptor noise as a determinant of colour thresholds. Proc. R. Soc. B Biol. Sci.

1179 Vorobyev M, Osorio D, Bennett ATD, Marshall NJ, Cuthill IC. 1998. Tetrachromacy, oil droplets and bird plumage colours. J. Comp. Physiol. - A Sensory, Neural, 
Behav. Physiol.

1182 Wachtler T, Doi E, Lee TW, Sejnowski TJ. 2007. Cone selectivity derived from the responses of the retinal cone mosaic to natural scenes. J. Vis.

1184

Wallace AR. 1879. Colour in nature. Nature. 19:501-5

Wässle H, Puller C, Müller F, Haverkamp S. 2009. Cone contacts, mosaics, and territories of bipolar cells in the mouse retina. J. Neurosci. 29(1):106-17

Werblin FS, Dowling JE. 1969. Organization of the retina of the mudpuppy, Necturus maculosus. II. Intracellular recording. J Neurophysiol. 32(3):339-55

Wilby D, Roberts NW. 2017. Optical influence of oil droplets on cone photoreceptor sensitivity. J. Exp. Biol.

Wilkie SE, Robinson PR, Cronin TW, Poopalasundaram S, Bowmaker JK, Hunt DM. 2000. Spectral tuning of avian violet- and ultraviolet-sensitive visual pigments. Biochemistry

Wong KY, Dowling JE. 2005. Retinal bipolar cell input mechanisms in giant danio. III. ON-OFF bipolar cells and their color-opponent mechanisms. J. Neurophysiol. 94(1):265-72

Wyszecki G, Stiles WS. 1982. Color Science. Wiley, New York

Yazulla S. 1976. Cone input to bipolar cells in the turtle retina. Vision Res. 16(7):737IN3

Yin L, Smith RG, Sterling P, Brainard DH. 2009. Physiology and morphology of color-opponent ganglion cells in a retina expressing a dual gradient of $\mathrm{S}$ and $\mathrm{M}$ opsins. J. Neurosci. 29(9):2706-24

Yokoyama S. 2000. Molecular evolution of vertebrate visual pigments Yovanovich CAM, Koskela SM, Nevala N, Kondrashev SL, Kelber A, Donner K. 
1205 2017. The dual rod system of amphibians supports colour discrimination at the 1206 absolute visual threshold. Philos. Trans. R. Soc. B Biol. Sci.

1207 Zana Y, Ventura DF, De Souza JM, Devoe RD. 2001. Tetrachromatic input to turtle 1208 horizontal cells. Vis. Neurosci.

1209 Zimmermann MJY, Nevala NE, Yoshimatsu T, Osorio D, Nilsson D-E, et al. 2018.

1210 Zebrafish Differentially Process Color across Visual Space to Match Natural

1211 Scenes. Curr. Biol. CB. 28(13):2018-2032.e5

1212 Zrenner E, Gouras P. 1981. Characteristics of the blue sensitive cone mechanism in primate retinal ganglion cells. Vision Res. 21(11):1605-9 